\title{
Goal Commitment Mediates the Relationship between Expected Positive Consequences of Goal Attainment and Effort
}

\author{
Nikola Fabiny, Ladislav Lovaš \\ Pavol Jozef Šafárik University in Košice, Slovak Republic
}

\begin{abstract}
Expected positive consequences are predictors of effort expenditure in goal pursuit (Sheldon \& Elliot, 1999). However, there are indications that this relationship is moderated (Locke \& Latham, 1990) or mediated by commitment. A sample of 388 university students was administrated questionnaires in order to measure goal commitment, effort and positive expected goal attainment consequences. The results suggest that goal commitment is not a moderator of the relationship between positive expected goal attainment consequences and exerted effort but rather mediates the relationship. The findings outline that expected consequences in terms of cost-benefit analysis as another type of expectations are associated with effort, too.
\end{abstract}

Key words: goal commitment, effort, expected goal attainment consequences

\section{Introduction}

Thinking about the future can influence decisions about future behavior (Oettingen et al., 2009; Austin \& Vancouver, 1996). Previous research on future thoughts has mainly been focused on expectancy judgments. According to expectancy-value theories, these judgments are predictors of intention formation and the process of goal attainment, including effort expenditure (Liberman \& Förster, 2012; Oettingen \& Mayer, 2002; Bandura, 1997). In the area of goal pursuing, future oriented expectancies consist

Acknowledgement

The paper is a part of the grant project VEGA $1 / 0924 / 15$ Self-regulation processes in attaining of distal goals.

Correspondence concerning this article should be addressed to Mgr. Nikola Fabiny, Pavol Jozef Šafárik University in Košice, Faculty of Arts, Department of Psychology, Moyzesova 9, 04059 Košice, Slovak Republic, E-mail: nikola.fabiny@gmail.com

Received June 29, 2017 of the anticipation of goal attainment as well as judgments of the consequences of goal attainment (Oettingen \& Mayer, 2002; Fontaine \& Dodge, 2006; Crick \& Dodge, 1994). This raises the question if the expected consequences of goal attainment itself are related to effort expenditure. As such, it has been hypothesized that expected positive consequences are predictors of effort expenditure (Sheldon \& Elliot, 1999).

An important issue is whether the relationship between the expected consequences of goal attainment and effort expenditure is direct or if this relationship is influenced (modified) by other variables. It is known that commitment plays an important role in the relationship between goals and effort. According to Locke and Latham (1990), the relationship between a goal and exerted effort is strongest if people are committed to their goals. It elicits the question whether goal commitment also has an important role in the relationship between the expected consequences of goal attainment and exerted effort. Locke and Latham (1990) have noted that commitment is a moderator in the relationship between goals and 
goal attainment, as well as exerted effort. It indicates the differences between people with low and high levels of commitment in this relationship. Therefore, it is possible to consider that commitment could also be a moderator in the relationship between positive expectations and effort. Alternatively, commitment could be an intervening variable in the relationship between expected consequences and effort. According to several authors, commitment can vary in the process of goal pursuit, and the expectations related to goal attainment belong to the antecedents of commitment as well (Fishbach \& Finkelstein, 2012; Klein et al., 1999). In this relationship between commitment and effort, it seems that stronger commitment is a condition for an increase in effort. Hence, a hypothesis was constructed where commitment was an interface in the relationship between expected positive consequences and effort. Our current aim was to confirm this assumption as a model in which commitment is a mediator in the relationship between positive expectations related to goal attainment and effort expenditure.

\section{Goal Expectations}

According to several psychological theories, the anticipation of future events is an important part in the direction of future activities (Oettingen \& Mayer, 2002; Austin \& Vancouver, 1996). The estimation of subjective probability as a judgment about whether a specific outcome is likely to occur has been the most common approach (Locke \& Latham, 2002). However, thinking about goal attainment has a more complex character. Part of it is anticipation of emotions, which can be elicited by a certain behavior or event. Baumgartner et al. (2008) have called them anticipated emotions. Strathman et al. (1994) have proposed a more widely defined construct called the Consideration of Future Consequences (CFC) and a scale for its assess- ment. Anticipated consequences play an important role also in social-cognitive information processing models in the sphere of aggressive behavior (Fontaine \& Dodge, 2006; Crick \& Dodge, 1994).

It is apparent that the anticipation of future behavior consequences is also related to goal pursuit (Beyth-Marom et al., 1993). Goal attainment consequences can be characterized as a kind of "cost benefit analysis" (comparison of positive to negative consequences ratio). It is supposed that positive expected consequences have a motivational effect and thus stimulate a behavior whereas expected negative consequences inhibit a behavior or result in avoidance (e.g., Rutter \& Hine, 2005; Archer et al., 2010; Lovaš et al., 2011). The terms positive and negative consequences are similar to the terms positive and negative feedback (Fishbach \& Finkelstein, 2012) and expected positive consequences are similar to the term of expected rewards. Rewards are usually studied in the context of their motivational effect on one's subsequent performance.

Hence, in the field of goal pursuit it can be supposed that the expectation of positive consequences fosters activities leading to goal attainment. In contrast, the expectation of largely negative consequences inhibits the goal directed behavior. The representation of goal attainment is associated with the anticipated positive consequences, whereas the representation of failure in attaining a goal is associated with negative anticipated consequences (e.g., Huang, in Pekrun et al., 2014).

\section{Commitment}

According to the Goal Setting Theory the relationship of goal - behavior (performance) is strongest when people are committed to their goal (Locke \& Latham, 2002). As Locke et al. (1988) have mentioned, commitment is an essential condition of goal attainment because 
when there is no commitment, a goal cannot have a motivational effect. Goal attainment has widely been defined as one's determination to attain a goal (Locke \& Latham, 1990). Commitment can also be defined as "a volitional psychological bond reflecting dedication to and responsibility for a particular target" (Klein et al., 2012, p. 137).

Commitment has a crucial influence on goal pursuit and is considered a prerequisite for its successful attainment (Oettingen et al., in Burkley et al., 2013). This is because individuals with a high level of commitment expend more effort on goal attainment, possess a greater extent of persistence and are thus more likely to accomplish the goal than persons with a lower level of commitment (Fishbach \& Dhar; Klinger, in Burkley et al., 2013).

In the context of the role of commitment in the relationship between thinking about the future and effort expenditure, the question about its antecedents is important. Klein et al. (1999) used an expectancy theory framework to identify the determinants of goal commitment. As the most proximal antecedents of goal commitment they analyzed the attractiveness of goal attainment and the expectancy of goal attainment. The relationship of these variables to motivation has been empirically confirmed several times (Klein et al., 1999; Hollenbeck \& Klein, 1987; Locke et al., 1981).

The identification of the antecedents of goal commitment is associated with its flexibility. This is done through possible changes in the attractiveness of goal attainment and the expectancy of goal attainment while pursuing a goal. This allows us to think about goal commitment as a mediator in the relationship between expected positive consequences and effort expenditure. Based on this, the aim of the presented research is to confirm the role of commitment as a moderator, as well as a mediator in the relationship between expected positive consequences and effort expenditure.

\section{Method}

The research sample consisted of 388 university students (140 men and 247 women, one participant did not enter their gender, $M=21.01$ years, $S D=1.58)$. The participants were students from three universities in Košice (Pavol Jozef Šafárik University, the Technical University and The University of Veterinary Medicine and Pharmacy). The statistical analyses (with the exception of the confirmatory factor analysis) were conducted in SPSS 21 using Process Macro (Hayes, 2013) and included correlations (Pearson's coefficient), moderation and mediation analysis.

The questionnaire contained a description of the goal chosen by researchers (successful graduation) to which all the items of the scales were related. Based on the connection between goal attainment representation and the positive anticipated consequences (Huang, in Pekrun et al., 2014), only positive consequences were assessed regarding goal successful attainment.

The original "Expected Positive Consequences of Academic Goal Attainment scale" consists of 12 items inspired by measuring the expected consequences in aggression research (e.g., Archer et al., 2010, e.g., "People closest to me would appreciate it.") and by conducting interviews with 20 university students (e.g., "I would be rewarded by someone (school, parents)."). The participants were asked to rate the probability of each of the 12 items $(1=$ very unlikely, $6=$ very likely; Cronbach's alpha $=.84$ ). The scale forms 3 factors according to the exploratory factor analysis - Positive evaluation by others, Positive self-esteem and Objective benefits (Fabiny \& Lovaš, 2017). The scale including the items' affinity to the factors is in the Appendix.

As a type of validity testing, a confirmatory factor analysis (CFA) was conducted using SPSS Amos 21. Based on previous reliability 
and factor analysis (Fabiny \& Lovaš, 2017), one item was deleted from the scale. In spite of the three factors shown by the exploratory factor analysis, the CFA confirmed the suitability of only one factor for subsequent analysis. Factor 1 "Positive evaluation by others" consists of 5 (originally 6) items and explained $19 \%$ of variance (the most of all the factors) as well as being reliable $(\alpha=.82)$. The CFA tested whether all the items loaded on the factor. As presented in Table 1 and Figure 1, the model showed an acceptable fit, supporting the internal validity

Table 1 Model fit coefficients for CFA of the scale Positive evaluation by others

\begin{tabular}{lr}
\hline Coefficient & Value \\
\hline CMIN/DF & 4.05 \\
RMR & $\mathbf{. 0 3}$ \\
SRMR & $\mathbf{. 0 3}$ \\
GFI & $\mathbf{. 9 8}$ \\
AGFI & $\mathbf{. 9 4}$ \\
CFI & $\mathbf{. 9 8}$ \\
PRATIO & .40 \\
PNFI & .39 \\
PCFI & .39 \\
NCP & 12.18 \\
RMSEA & .09 \\
PCLOSE & $\mathbf{. 0 6}$ \\
AIC & 38.18 \\
\hline
\end{tabular}

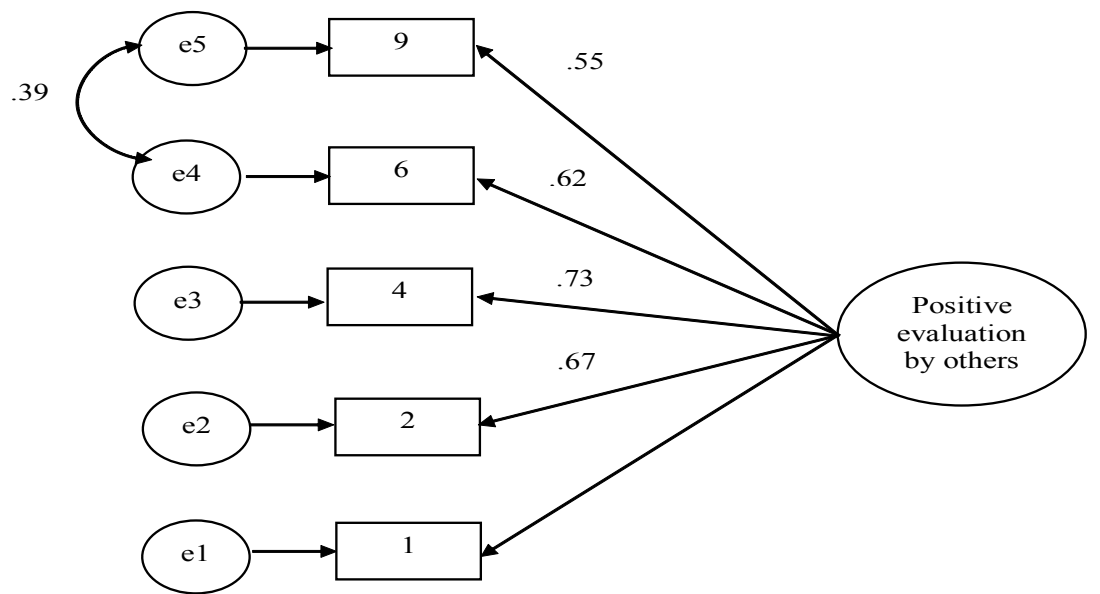

Note: Variables in the rectangles are numbers of items in the scale; standardized regression weights are displayed

Figure 1 CFA of the first factor of the Expected Positive Consequences of Academic Goal Attainment scale 
of the scale $\left(\chi^{2}=16.18, \mathrm{df}=4\right)$ even though it was significant $(p=.003)$.

Goal commitment was measured by the KUT (Klein Unidimensional Target-free measure) scale (Klein et al., 2014) and consists of four items ("How committed are you to this target?; To what extent do you care about this target?; How dedicated are you to this target?; To what extent have you chosen to be committed to this target?"). The statements were rated on a 6 -point scale ( $1=$ not at all, $6=$ completely; $\alpha=$ $.80)$.

Effort was rated on a 6-point scale $(1=$ not much, $6=\mathrm{a}$ lot; $\alpha=.91)$. The three items which represent effort have been adopted from Nelissen et al. (2011) and their scale concerning body weight. It has been modified for the present study to measure effort in general ("How much effort do you make to achieve your target (weight)?; To what extent do you do your best to attain your target (weight)?; How much energy do you spend achieving your target (weight)?").

Note: In the research, more scales concerning goal characteristics were administrated but for the current study these three are considered the most important.

\section{Results}

Firstly, we focused on the relationships among the three measured variables. Table 2 displays the correlations between the first factor of the expected positive consequences of academic goal attainment, goal commitment and effort, which were all significant.

According to Locke and Latham (2006), we tested a moderation model. The moderation model is significant $(B=.11 ; S E=.05 ; 95 \% C I$ $[.01 ; .21] ; p=.04)$ and the determination coefficient changed after adding the interaction into the equation only by $1 \%\left(R^{2}\right.$ change $\left.=.01\right)$. The effect size $f^{2}=.01$ is, according to Cohen (1988), weak. Thus, it seems that goal commitment moderates the relationship between the expected positive consequences of academic goal attainment ( $1^{\text {st }}$ factor) and effort even though the moderation effect is weak. The unstandardized coefficients $B$ were $B=.20$ for commitment and $B=-.47$ for the first factor of the expected positive consequences of academic goal attainment. Figure 2 depicts the interaction (slopes).

Following the correlation analyses and testing of the moderation model, the proposed mediation model was tested. Figure 3 supplemented by Table 3 illustrates the full mediation of commitment in the relationship between the expected positive consequences of academic goal attainment ( $1^{\text {st }}$ factor $)$ and effort, i.e. the significance of the indirect effect mediated by commitment in contrast to the insignificant direct effect $(B=$ $-.02, S E=.06,95 \% C I[-.14 ; .09], p=.68)$ of the first factor of the expected positive conse-

Table 2 Correlations between expected positive consequences of academic goal attainment ( $1^{\text {st }}$ factor), goal commitment and exerted effort

\begin{tabular}{lcccc}
\hline & & $\begin{array}{c}\text { Consequences } \\
1^{\text {st }} \text { factor }\end{array}$ & Commitment & Effort \\
\hline Consequences & $\mathrm{r}_{\mathrm{xy}}$ & 1 & & \\
$1^{\text {st }}$ factor & Sig. & .37 & 1 & \\
Commitment & $\mathrm{r}_{\mathrm{xy}}$ & .0001 & .62 & \\
& Sig. & .21 & .0001 & 1 \\
Effort & $\mathrm{r}_{\mathrm{xy}}$ & .0001 & & \\
\hline
\end{tabular}




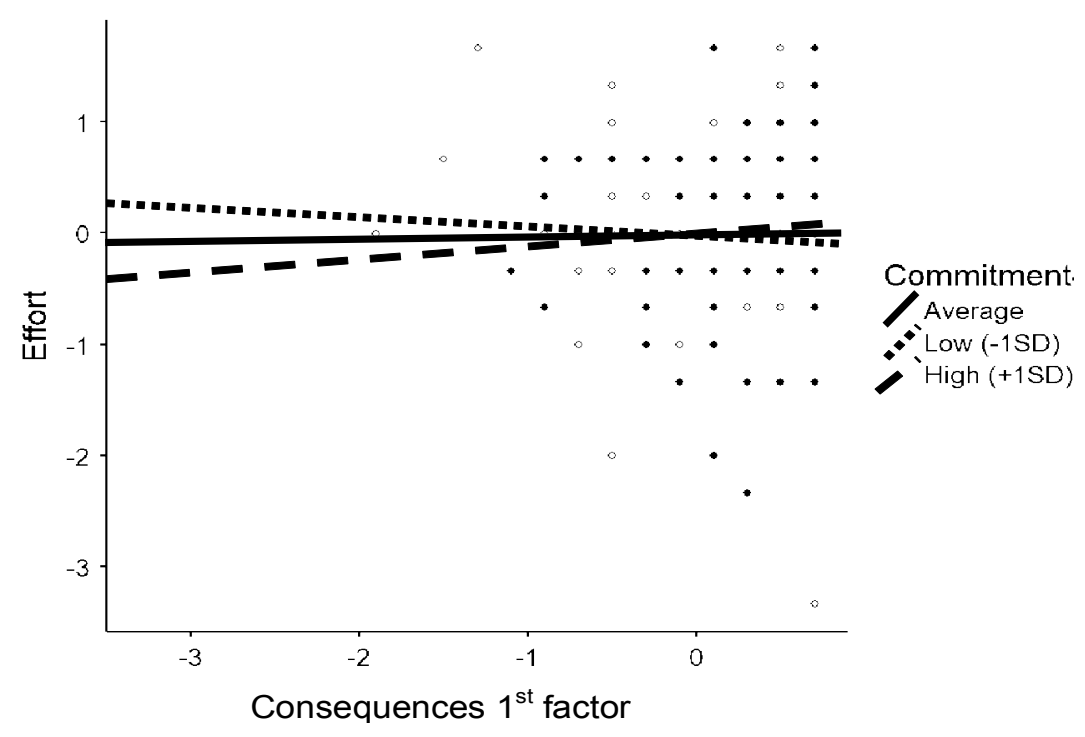

Figure 2 Moderating effect of commitment in the prediction of effort by expected positive consequences of academic goal attainment

Table 3 Indirect effect on effort

\begin{tabular}{ccc}
\hline Indirect effect & Estimate (SE) & $95 \% \mathrm{CI}$ \\
\hline & $.32(.05)$ & {$[.23 ; .42]$}
\end{tabular}

Sobel's test $Z=6.95 ; p \leq .0001$

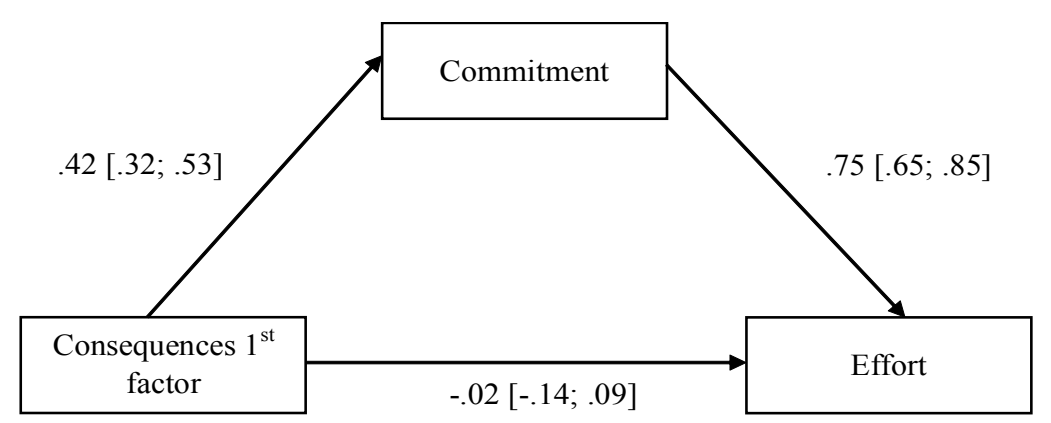

Figure 3 Mediating effect of commitment in the prediction of effort by expected positive consequences of academic goal attainment 
quences of academic goal attainment on effort. The $95 \% \mathrm{CI}$ for the direct effect including .0 supports the non-significance of the direct effect, whereas the $95 \%$ CI for the indirect effect missing value .0 confirms that the indirect effect is significant. This suggests that the more positive consequences of (academic) goal attainment are expected, the more effort will be exerted because people are more committed to goals related to positive expectancies. The effect size analysis revealed a strong mediation effect (Cohen's $f^{2}=.56 ; R_{A}^{2}=.05 ; R_{A B}^{2}=.39$ ).

\section{Discussion}

The results of this study support the role of goal commitment in the relationship between expected consequences of goal attainment and exerted effort. Goal commitment both moderated (in accordance with the findings of Locke and Latham, 2006) and mediated (consistent with Klein et al., 1999 findings about commitment's antecedents) this relationship.

A full mediation was demonstrated, i.e. the non-significant direct effect of expected consequences of goal attainment on effort and a significant indirect effect via commitment. This is also consistent with the correlation analysis where all the correlations were significant. However, the relationship between expected consequences and effort was very weak in contrast to the relationships with commitment, which had higher correlation coefficient values. The Sobel test showed that the indirect effect of expected consequences on effort through commitment was significant, which could be partly attributed to the large sample size. According to Cohen (1988), $f^{2}$ is the effect size attributable to the addition of the mediator variable to the model meaning that the effect of the mediator in the study was large.

The present findings both support the hypotheses about the role of commitment and confirm the role of expectancies in the domain of goals. While commitment and effort are variables typically studied in goal research, the expected consequences (of goal attainment) have not been studied much in this context. Expected consequences are a part of goal choice. Thus, the choice of a goal - an integral part of the decision-making process with its supposed effect on goal pursuit - brings a different point of view to the initial motivation in goal directed behavior. As explained above, expectations (in terms of subjective probability) have a relationship to effort exerted on a goal attainment (Sheldon \& Elliot, 1999). The study suggests that expected consequences, operationalized above (in terms of cost-benefit analysis) as another type of expectation, are associated with effort, too.

We are aware of the limitations of the present study concerning several issues. Even though the research sample was relatively large $(n=$ 388 participants), it consisted of only university students. This makes the opportunity to generalize the findings rather complicated. On the other hand, there is no evidence for studying the topic on a specific population, since the knowledge in the field is considered general and research is carried out on a "normal" (non-specific) population of which students are a representative example. We should also mention the disadvantages of self-report questionnaires, one of which is the goal given by the researchers instead of an idiographic approach.

The limitation of self-reports could be eliminated by arranging an experimental design, i.e. manipulation with an independent variable, i.e. expected consequences of goal attainment in the present study. We suggest several other perspectives for future research. In the hypothesized model we did not consider the possibility of the simultaneous operation of two types of goal pursuit related expectancies - expected emotions (e.g., Perugini \& Bagozzi, 2004) and expected consequences. There is evidence that these two variables could operate in parallel in 
goal pursuits. Furthermore, in the current research we only considered positive expected consequences as being relevant in goal successful attainment (consistent with Huang, in Pekrun et al., 2014) but there is a call which needs to be verified. Is goal attainment only associated with positive anticipated consequences? What is the role of negative anticipated consequences in goal attainment?

The term goal attainment itself brings other points worth thinking about. Firstly, we tend to approach goal attainment as a synonym of goal pursuit and use it alternatively. We have studied the anticipated consequences regarding the representation of goal attainment as a result. However, a question arises whether the anticipated consequences related to goal pursuit as a process could also be distinguished. The hypothesis of temporal change of expected consequences in the process of goal pursuit could be based on findings of e.g., Carrera et al. (2012), who describe differences in intensity as well as polarity of anticipated emotions concerning different stages of the process (of risk alcohol consumption). Secondly, while we focused on goal attainment, a representation of failure in goal attainment itself could be an object of research interest.

\section{Conclusion}

The first factor Positive evaluation by others of the original Expected Positive Consequences of Academic Goal Attainment scale predicts an effort indirectly through goal commitment. The results show that the more positive consequences of goal attainmentare expected, the more people are committed to that goaland, in turn, the more effort they exert to achieve the goal.

\section{References}

Archer, J., Fernández-Fuertes, A. A., \& Thanzami, V. L. (2010). Does cost-benefit analysis or self-con- trol predict involvement in two forms of aggression? Aggressive Behavior, 36, 292-304.

Austin, J. T., \& Vancouver, J. B. (1996). Goal constructs in psychology: Structure, process, and content. Psychological Bulletin, 120, 338-375.

Bandura, A. (1997). Self-efficacy: The exercise of control. New York: Freeman.

Baumgartner, H., Pieters, R., \& Bagozzi, R. P. (2008). Future-oriented emotions: Conceptualization and behavioral effects. European Journal of Social Psychology, 38, 685-696.

Beyth-Marom, R., Austin, L., Fischhoff, B., Palmgren, C., \& Jacobs-Quadrel, M. (1993). Perceived consequences of risky behaviors: Adults and adolescents. Developmental Psychology, 29, 549-563.

Burkley, E., Anderson, D., Curtis, J., \& Burkley, M. (2013). Vicissitudes of goal commitment: Satisfaction, investments, and alternatives. Personality and Individual Differences, 54, 663-668.

Carrera, P., Cabalero, A., \& Muňoz, D. (2012). Futureoriented emotions in the prediction of binge-drinking intention and expectation: The role of anticipated and anticipatory emotions. Scandinavian Journal of Psychology, 53, 273-279.

Cohen, J. E. (1988). Statistical power analysis for the behavioral sciences. Hillsdale, NJ: Lawrence Erlbaum Associates, Inc.

Crick, N. R., \& Dodge, K. A. (1994). A review and reformulation of social information-processing mechanisms in children's social adjustment. Psychological Bulletin, 115, 74-101.

Fabiny, N., \& Lovaš, L. (2017). Očakávané dôsledky dosiahnutia akademického ciel'a a ich štruktúra. Sociálne procesy a osobnost' 2016. Bratislava: Ústav experimentálnej psychológie, Centrum spoločenských a psychologických vied SAV, 99-106.

Fishbach, A., \& Finkelstein, S. R. (2012). How feedback influences persistence, disengagement, and change in goal pursuit. In H. Aarts \& A. J. Elliot (Eds.), Goal-directed behavior (pp. 203-230). New York: Psychology Press.

Fontaine, R. G., \& Dodge, K. A. (2006). Real-time decision making and aggressive behavior in youth: A heuristic model of Response Evaluation and Decision (RED). Aggressive Behavior, 32, 604-624.

Hayes, A. F. (2013). Introduction to mediation, moderation, and conditional process analysis: $A$ regression-based approach. New York: The Guilford Press.

Hollenbeck, J. R., \& Klein, H. J. (1987). Goal commitment and the goal-setting process: Problems, prospects, and proposals for future research. Journal of Applied Psychology, 72, 212-220.

Klein, H. J., Wesson, M. J., Hollenbeck, J. R., \& Alge, B. J. (1999). Goal commitment and the goalsetting process: Conceptual clarification and em- 
pirical synthesis. Journal of Applied Psychology, 84, 885-896.

Klein, H. J., Molloy, J. C., \& Brinsfield, C. T. (2012). Reconceptualizing workplace commitment to redress a stretched construct: Revisiting assumptions and removing confounds. Academy of Management Review, 37, 130-151.

Klein, H. J., Cooper, J. T., Molloy, J. C., \& Swanson, J. A. (2014). The assessment of commitment: Advantages of a unidimensional, target-free approach. Journal of Applied Psychology, 99, 222-238.

Liberman, N., \& Förster, J. (2012). Goal gradients, expectancy, and value. In H. Aarts \& A. J. Ellio (Eds.), Goal-directed behavior (pp. 151-174). New York: Psychology Press.

Locke, E. A., Shaw, K. N., Saari, L. M., \& Latham, G. P. (1981). Goal setting and task performance: 1969 - 1980. Psychological Bulletin, 90, 125-152.

Locke, E. A., Latham, G. P., \& Erez, M. (1988). The determinants of goal commitment. Academy of Management Review, 13, 23-39.

Locke, E. A., \& Latham, G. P. (1990). A theory of goal setting and task performance. Englewood Cliffs, NJ: Prentice Hall International.

Locke, E. A., \& Latham, G. P. (2002). Building a practically useful theory of goal setting and task motivation. A 35-year odyssey. American Psychologist, 57, 705-717.

Locke, E. A., \& Latham, G. P. (2006). New directions in Goal-Setting Theory. Current Directions in Psychological Science, 15, 265-268.

Lovaš, L. et al. (2011). Osobné a situačné kontexty sebakontroly. Košice: Univerzita Pavla Jozefa Šafárika v Košiciach.

Nelissen, R. M. A., de Vet, E., \& Zeelenberg, M. (2011). Anticipated emotions and effort allocation in weight goal striving. British Journal of Health Psychology, 16, 201-212.

Oettingen, G., \& Mayer, D. (2002). The motivating function of thinking about the future: Expectations versus fantasies. Journal of Personality and Social Psychology, 83, 1198-1212.

Oettingen, G., Mayer, D., Sevincer, A. T., Stephens, E. J., Pak, H., \& Hagenah, M. (2009). Mental contrasting and goal commitment: The mediating role of energization. Personality and Social Psychology Bulletin, 35, 608-622.

Pekrun, R., Cusack, A., Murayama, K., Elliot, A. J., \& Thomas, K. (2014). The power of anticipated feedback: Effects on students' achievement goals and achievement emotions. Learning and Instruction, 29, 115-124.

Perugini, M., \& Bagozzi, R. P. (2004). An alternative view of pre-volitional processes in decision making: Conceptual issues and empirical evidence. In G. Haddock \& G. R. Maio (Eds.), Contemporary perspectives on the psychology of attitudes: The Cardiff symposium (pp. 1-50). Hove, UK: Psychology Press.

Rutter, A., \& Hine, D. W. (2005). Sex differences in workplace aggression: An investigation of moderation and mediation effects. Aggressive Behavior, 31, 254-270.

Sheldon, K. M., \& Elliot, A. J. (1999). Goal striving, need satisfaction, and longitudinal well-being: The self-concordance model. Journal of Personality and Social Psychology, 76, 482-497.

Strathman, A., Gleicher, F., Boninger, D. S., \& Edwards, C. S. (1994). The consideration of future consequences: Weighing immediate and distant outcomes of behavior. Journal of Personality and Social Psychology, 66, 742-752.

\section{Appendix}

The English translation of the Expected Positive Consequences of Academic Goal Attainment scale (originally administrated in Slovak language)

Factor 1: Positive evaluation by others

1. My surroundings would appreciate it.

2. I would get credit from people close to me, classmates.

4. People closest to me would appreciate it.

6. I would be satisfied that I have achieved something.

8. I would be satisfied that I have done something, got through it.*

9. I would be proud of myself.

Appendix continues 


\section{Appendix continued}

Factor 2: Positive self-esteem

7. I would improve my position compared to others.

10. I would be rewarded by someone (school, parents).

11. My self-esteem would improve.

12. I would be rewarded for that by myself(I would afford something to myself).

Factor 3: Objective benefits

3. It would improve my general knowledge in the field.

5. I would be better prepared for my future work life (career).

*Note: Based on reliability (item) analysis item No. 8 was deleted from the original 12 item scale. 